\title{
EVALUATION OF LINEAR KINETIC METHODS FROM PYROLYSIS DATA OF SPANISH OIL SHALES AND COALS
}

\author{
M. À. OLIVELLA, F. X. C. DE LAS HERAS* \\ Escola Politècnica Superior d'Enginyeria de Manresa \\ Department of Mining Engineering and Natural Resources \\ Universitat Politècnica de Catalunya \\ Av Bases de Manresa 61-73, 08242-Manresa, Catalonia, Spain
}

\begin{abstract}
This work involves a comparative study of six different linear methods: three methods based on several curves and three based on a single curve for deriving kinetic parameters from TG/DTG curves in the interval related to oil and hydrocarbon generation. Such methods were applied for interpretation of nonisothermal data obtained at pyrolysis of two Spanish coals and two samples of oil shale. In order to elucidate the most accurate methods based on a single TG/DTG curve, respective equations were simulated by the use of a simulation program. Although some of these methods were proposed more than 30 years ago, they are extensively used nowadays and useful for studying thermal degradation of solids. Comparison of experimental data with simulated curves shows that the differential method followed by the integral one proposed by Friedman, Popescu and Segal were the most accurate methods. In contrast, differential methods based on single and several curves developed by Vachusca, Voboril and Friedman, respectively, were considered the least accurate methods.
\end{abstract}

\section{Introduction}

Generally in thermogravimetry (TG) heterogeneous reactions as

$$
\mathrm{A}_{\text {(solid) }} \rightarrow \mathrm{B}_{\text {(solid) }}+\mathrm{C}_{(\text {gas })}
$$

are studied under nonisothermal conditions.

Usually the fractional reaction, $\alpha$, is defined in terms of the change in sample mass $\left[\alpha=\left(m_{0}-m\right) /\left(m_{0}-m_{\mathrm{f}}\right)\right]$ where $m_{0}$ is the initial mass and $m_{\mathrm{f}}$ the mass of the sample when reaction is completed.

The kinetic reaction (1) may be studied by using two types of approximations: model and homogeneous approximations.

\footnotetext{
* Corresponding author: e-mail heras@emrn.upc.edu
} 
By using the first approach, kinetic equations are derived taking into account the nucleation, the growth of germs, or the diffusion of the product [1-3].

The last approach of homogeneous kinetics is applied by considering that the reaction rate, defined by means of the conversion degree $(\alpha)$, might be given as the product of an apparent rate constant, depending on the temperature and a certain conversion function as indicated by the following equation:

$$
\mathrm{d} \alpha / \mathrm{d} t=k(T) f(\alpha),
$$

where $f(\alpha)$ is a differential function of the conversion degree and $k(T)$ is a function of rate coefficient of temperature.

The temperature dependence is expressed according to Arrhenius equation:

$$
k(T)=A \exp (-E / R T),
$$

and very often the conversion function is presumed to be an $n$-th order homogeneous reaction:

$$
f(\alpha)=(1-\alpha)^{n} .
$$

For nonisothermal experiments a convenient change of the variable time $(t)$ into temperature ( $T$ ) turns Eq. (2) into

$$
\mathrm{d} \alpha / \mathrm{d} T=\frac{1}{\beta} k(T) f(\alpha),
$$

where $\beta$ is the heating rate.

Introducing into Eq. (5) Arrhenius equation and the function $f(\alpha)$ as given by Eq. (3) and Eq. (4) respectively, Eq. (6) is obtained:

$$
\mathrm{d} \alpha / \mathrm{d} T=A \frac{1}{\beta} \exp (-E / R T)(1-\alpha)^{n} .
$$

According to Eq. (6), from the kinetic point of view the reaction (1) may be characterized by means of three parameters, $A$ (pre-exponential order; $1 / \mathrm{min}$ ), $E$ (activation energy; $\mathrm{kJ} / \mathrm{mol}$ ) and $n$ (reaction order). From the mathematical point of view, calculation of the above parameters requires the use of a variational method, by choosing a family of functions and by determining parameter values ensuring the minimum deviation of experimental points from the theoretical curve.

Consequently, the constants $A, E$ and $n$ are related to the whole complexity of processes occurring during the pyrolysis experiments but have no clear meaning when related to the chemical reaction itself. Hence they are designated as apparent values $[4,5]$. Thermogravimetry (TG/DTG) has been 
shown to be a useful technique to study the pyrolysis and combustion of fossil fuels [6-10].

Although linear methods to derive the kinetic analysis from TG data were developed many years ago [5, 7, 11-14], they are extensively used nowadays in studying kinetic analysis of polymers decomposition [15-21]. Despite their popularity, there are cast doubts on the accuracy of the approximations on which the linear methods are based because they provide significant deviations in the determination of kinetic parameters. Nevertheless, detailed studies to evaluate the accuracy of the linear methods (both differential and integral) and to compare them critically are still missing.

In the present work, pyrolysis of Spanish coals and oil shales were studied by using TG/DTG curves; in addition kinetic parameters were estimated in the interval related to oil and hydrocarbon generation and compared by means of several linear methods taken from the literature: six integral and differential methods (three based on a single experimental curve and the other three based on several experimental curves) described below. Additionally, in order to elucidate the most accurate methods based on a single curve, simulations of the equations were achieved by using Simnon program.

The kinetic analysis based on one point, the maximum temperature of oil and hydrocarbon generation, has been described elsewhere for the same fossil fuels [22].

\section{Methods for the analysis of TG/DTG data}

\section{Data acquired from a single experiment}

\section{Differential Method}

This method is based on Eq. (5) written in the logarithmic form:

$$
\ln \left[\frac{1}{f(\alpha)} \frac{\mathrm{d} \alpha}{\mathrm{d} T}\right]=-\frac{E}{R T}+\ln \frac{A}{\beta} .
$$

The plot

$$
\left\{\ln \left[\frac{1}{f(\alpha)} \frac{\mathrm{d} \alpha}{\mathrm{d} T}\right] \text { vs. }-\frac{1}{T}\right\}
$$

gives various correlation coefficients. By considering the analytical form of $f(\alpha)$ given by Eq. (4), the value of the $n$ constant corresponds to the maximum value of the correlation coefficient obtained, and the plot determined for that $f(\alpha)$ allows to evaluate the value of the apparent activation energy, $E$. The intercept gives the value of the apparent 
preexponential factor, $A$. This method was firstly described by Friedman [12].

\section{Using the differential operator}

The use of the differential operator in a differential equation leads to the socalled double differential methods. By applying this operator in Eq. (6) one obtains:

$$
T^{2} \frac{\mathrm{d}^{2} \alpha / \mathrm{d} T^{2}}{\mathrm{~d} \alpha / \mathrm{d} T}=\frac{E}{R}-\frac{n}{1-\alpha} \frac{\mathrm{d} \alpha}{\mathrm{d} T} T^{2} .
$$

The plot

$$
\left[T^{2} \frac{\mathrm{d}^{2} \alpha / \mathrm{d} T^{2}}{\mathrm{~d} \alpha / \mathrm{d} T}\right] \text { vs. }\left[\frac{1}{1-\alpha} \frac{\mathrm{d} \alpha}{\mathrm{d} T} T^{2}\right]
$$

leads to a straight line whose slope gives the value of reaction order, $n$, and the intercept allows to evaluate the value of apparent activation energy, $E$. This method has been developed by Vachusca and Voboril [23].

\section{Integral method}

This method is based on Eq. (5) written in an integral form:

$$
\int_{\alpha_{m}}^{\alpha_{n}} \frac{\mathrm{d} \alpha}{f(\alpha)}=\frac{A}{\beta_{m n}} \int_{T_{m}}^{T_{n}} \exp (-E / R T) \mathrm{d} T,
$$

where $\int_{\alpha_{m}}^{\alpha_{b}} \frac{\mathrm{d} \alpha}{f(\alpha)}=g_{m n}$.

The temperature integral, from the right side member of Eq. (9) will be evaluated using the first mean value theorem for definite integrals

$$
\oint_{m n}=\left(T_{m}-T_{n}\right) \exp \left(-E / R T_{i}\right) .
$$

Introducing Eq. (9) into Eq. (10) and taking the logarithms one obtains

$$
\ln g_{m n}(\alpha)-\ln \left(T_{n}-T_{m}\right)=\frac{-E}{R T_{i}}+\ln \left(\frac{A}{\beta_{m n}}\right),
$$

where $T_{i} \in\left[T_{m}, T_{n}\right]$. The value of $T_{i}$ can be approximated by taking the average

$$
T_{i}=\frac{T_{m}+T_{n}}{2} .
$$

The plot 


$$
\left\{\ln \left[g_{m n}(\alpha) /\left(T_{n}-T_{m}\right)\right] \text { vs. } 1 / T_{i}\right\}
$$

taking into account that $g(\alpha)=\left[1-(1-\alpha)^{1-n}\right] /(1-n)$, leads to one straight line with the respective correlation coefficient. The slope equal to $E / R$ allows to calculate the value of apparent activation energy, $E$, and the intercept equal to $\ln \left(A / \beta_{m n}\right)$ allows to calculate the value of the apparent preexponential factor, $A$.

This method has been proposed by Popescu and Segal [11].

\section{Data from experiments with linear heating rates 5,15 and $25 \mathrm{~K} / \mathrm{min}$}

The experimental data from experiments carried under $N$ various linear heating rates allow a family of $N$ curves to be drawn in the plane $(\alpha, T)$, as it is shown in Fig. 1:

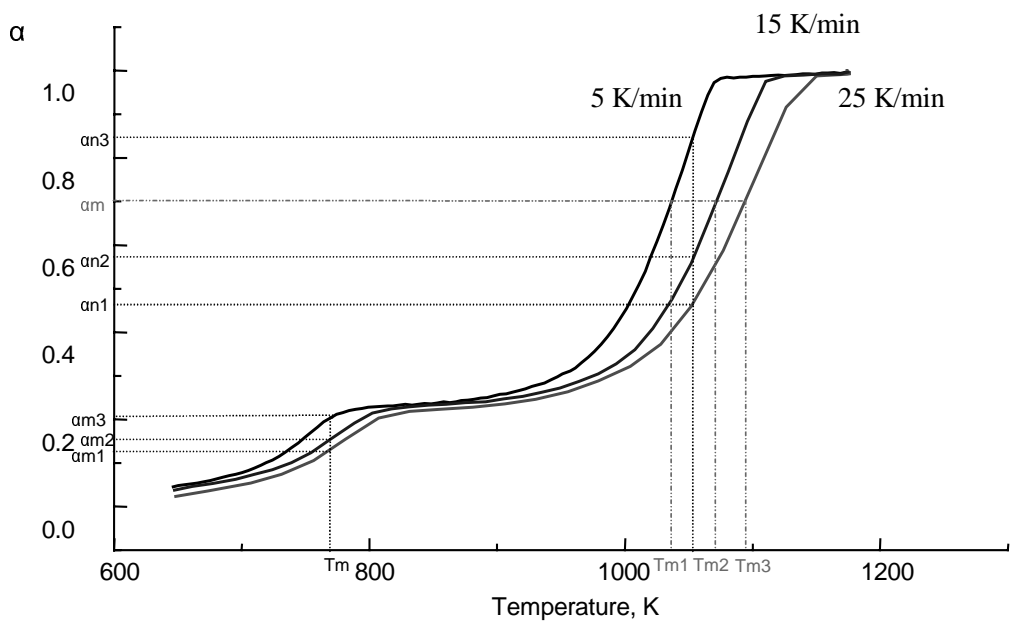

Fig. 1. Experimental $(\alpha, T)$ curves of 8-Me coal recorded at linear heating rates $(\beta)$ 5,15 and $25 \mathrm{~K} / \mathrm{min}$.

\section{Differential method}

Eq. (2) written in a slight modified form leads to

$$
\left[\frac{\mathrm{d} \alpha}{\mathrm{d} T} \frac{1}{f(\alpha)}\right]=\frac{1}{\beta} k(T) .
$$

Eq. (13) may be used for obtaining separately the analytical form of $k(T)$ and those of $f(\alpha)$ by means of two conditions:

Using $T=$ constant: Parallel straight lines $T_{m}, T_{n}$, etc. intersect the family of $N$ experimental curves recorded at $N$ various heating rates and produce, 
for each $T$-line, a set of pairs $\left(\alpha_{m 1}, \beta_{1}\right) \ldots\left(\alpha_{m N}, \beta_{N}\right)$. For each set of pairs the plot

$$
\left[\frac{\mathrm{d} \alpha}{\mathrm{d} T} \frac{1}{f(\alpha)}\right]_{i} \text { vs. }\left[\frac{1}{\beta_{i}}\right] i \in\{1,2, \ldots, N\}
$$

will be a straight line of slope $k(T)$ and intercept zero for a proper choice of $f(\alpha)$.

The calculated slopes, which are, in fact, values of $k(T)$ at each used temperature may be used further for plotting

$$
\{\ln k(T) \text { vs. }(-1 / T)\} \text {. }
$$

The slope of this straight line allows to compute the value of the apparent activation energy, $E$, and the intercept equals to $\ln A$.

This method was also proposed by Popescu and Segal [11].

Using $\alpha=$ constant: In order to use this condition one has to draw parallel lines $\alpha_{m}=$ constant, $\alpha_{n}=$ constant, etc., which intersect the $N$ curves corresponding to $N$ heating rates, and for each line $\alpha_{m}=$ constant, a set of pairs $\left(T_{m 1}, \beta_{1}\right) \ldots .\left(T_{m N}, \beta_{N}\right)$ is obtained (Fig. 1).

The plot

$$
\left\{k(T) \quad \text { vs. } \quad \beta \frac{\mathrm{d} \alpha}{\mathrm{d} T}\right\}
$$

will be a straight line passing through the origin of the axes only for a proper choice of the analytical form of $k(T)$. If Eq. (3) is assumed to be valid for $k(T)$, Eq. (13) may be written in a logarithmic form as

$$
\ln \left[\beta \frac{\mathrm{d} \alpha}{\mathrm{d} T}\right]=\frac{-E}{R T}+\ln [A f(\alpha)],
$$

and the plot:

$$
\left\{\ln \left[\beta \frac{\mathrm{d} \alpha}{\mathrm{d} T}\right] \text { vs. }-1 / T\right\}
$$

allows to compute the value of apparent activation energy, E. From the intercept and the already determined analytical form of $f(\alpha)$ the value of the apparent pre-exponential factor, $A$, may be also calculated.

Eq. (14) has been proposed by Friedman [12].

Integral methods with linear heating rates

Equation (2) written in the integral form is

$$
\int_{\alpha_{m}}^{\alpha_{n}} \frac{\mathrm{d} \alpha}{f(\alpha)}=\frac{1}{\beta_{m n}} \int_{T_{m}}^{T_{n}} k(T) \mathrm{d} T .
$$


By taking into account that

$$
\int_{\alpha_{m}}^{\alpha_{n}} \frac{\mathrm{d} \alpha}{f(\alpha)}=g_{m n}(\alpha)
$$

and the evaluation of the temperature integral is written as:

$$
\oint_{m n}(T)=\int_{T_{m}}^{T_{n}} k(T) \mathrm{d} T,
$$

using Eq. (17) and (15) gives

$$
g_{m n}(\alpha)=\frac{1}{\beta_{m n}} \oint_{m n}(T)
$$

There are two possible ways to use Eq. (18) [24]:

Using $\Delta T=$ constant: This condition means that the pairs of lines $\left(T_{m}, T_{n}\right)$ are used to intersect the $N$ experimental recorded (con, $T$ ) curves, and they produce $N$ pairs of values $\left(\alpha_{m}, \alpha_{n}\right)$, where $N$ is the number of heating rates $\beta_{i}, i \in\{1,2, \ldots N\}$.

As $T_{m}$ and $T_{n}$ have the same value for all the $N$ pairs, the integral $\oint_{m n}(T)$ should be constant.

The plot:

$$
\left\{g_{m n}(\alpha)_{i} \quad \text { vs. } \frac{1}{\beta_{m n i}}\right\}
$$

where $g_{m n}(\alpha)$ is calculated for each pair of values $\left(\alpha_{m}, \alpha_{n}\right)$, should lead to a straight line of slope equal to $\oint_{m n}(T)$ and intercept equal to zero only for a proper form of $f(\alpha)$. The values of the slopes $\oint_{m n}(T)$ for each pair of temperatures $\left(T_{m}, T_{n}\right)$ may be further used for determining the proper analytical form of $k(T)$. The first mean value theorem for integrals allows to write the temperature integral as:

$$
\oint_{m n}(T)=\int_{T_{m}}^{T_{b}} k(T) \mathrm{d} T=\left(T_{b}-T_{m}\right) k\left(T_{i}\right),
$$

where $T_{i} \in\left[T_{m}, T_{n}\right]$. The plot $\left\{\ln \left[\oint_{m n} /\left(T_{n}-T_{m}\right)\right] v s .1 / T_{i}\right\}$ will be a straight line only if $k(T)$ verifies Arrhenius equation (Eq. (3)). The slope of the plot will be equal to $E / R$, and the value of the activation energy may be easily estimated. The intercept of the plot allows to obtain the value of the apparent preexponential factor, $A$.

Using $\Delta \alpha=$ constant: Pairs of lines $\left(\alpha_{m}, \alpha_{n}\right)$ intersect the experimental recorded (c, $T)$ and will produce $N$ pairs of $\left(T_{m}, T_{n}\right)$ one for each value of the $N$ heating rates $\beta_{i}, i \in\{1,2, \ldots N\}$. 
If the validity of Eq. (4) is accepted and the mean value theorem is used for the evaluation of the temperature integral as shown in Eq. (15), Eq. (18) becomes, after taking logarithms and appropriate arrangement of the terms:

$$
\operatorname{Ln}\left[\beta_{m n} / T_{n}-T_{m}\right]=-E / R T_{i}+\ln \left(A / g_{m n}\right) .
$$

The plot

$$
\left\{\operatorname{Ln}\left[\beta_{m n} / T_{n}-T_{m}\right] \text { vs. }-1 / T_{i}\right\}
$$

leads to a straight line whose slope allows to calculate the activation energy, $E$, for the range $\left(\alpha_{m}, \alpha_{n}\right)$. The value of $T_{\mathrm{i}}$ is approximated using Eq. (12). The values of the intercept $\mathrm{u}(\alpha)$ obtained for various pairs $\left(\alpha_{m}, \alpha_{n}\right)$, and equal to $\ln A / \mathrm{g}_{m n}(\alpha)$ allow to perform the plot

$$
\left\{u(\alpha) \text { vs. } \ln g_{m n}(\alpha)\right\} .
$$

The intercept equals $\ln A$.

\section{Experimental}

The designation, origin and kerogen type of different low maturity (vitrinite reflectance < 0.4) fossil fuels are shown in Table 1. Elemental analysis of carbon and hydrogen were carried out using a Fisons 1106, and the total sulfur was determined in an elementary analyzer Fisons 1108.

Samples studied were two coals from the Mequinenza and Utrillas basins and two oil shales from the Ribesalbes basin. Ribesalbes oil shales were previously decarbonated using $5 \mathrm{~N}$ hydrochloric acid. The Mequinenza (8-Me) coal bearing sequence is included in Los Monegros Lacustrine System (SE Ebre basin) and was deposited during Late Oligocene (ca. $30 \mathrm{Ma}$ ). Evaporitic facies were developed mainly in the marginal lacustrine zones while carbonate and lignite deposits were dominant in inner lacustrine areas [25].

Utrillas subbituminous coal (Cañizara) was taken from the Maestrazgo basin, which is located in the Iberian Range linking zone with the southernmost sector of the Catalan coastal range, deposited during Middle Albian

Table 1. $\mathbf{C}, \mathbf{H}$ and $\mathbf{S}$ percentages, on dry and ash free basis (d.a.f.) and kerogen type of Mequinenza and Utrillas coals and Ribesalbes oil shale

\begin{tabular}{|l|l|c|c|c|c|l|}
\hline \multicolumn{1}{|c|}{ Sample } & \multicolumn{1}{|c|}{ Basin } & Kerogen type & C & H & S & N \\
\hline 8-Me & Mequinenza & III-S & 60.6 & 5.3 & 13.4 & 1.0 \\
Cañizara & Utrillas & III & 73.2 & 5.8 & 5.4 & 0.69 \\
Rib-3 & Ribesalbes & I-S & 10.7 & 1.75 & 1.92 & 0.15 \\
Rib-7 & Ribesalbes & I-S & 10.3 & 2.38 & 0.33 & 0.66 \\
\hline
\end{tabular}


(late Lower Cretaceous, ca. $105 \mathrm{Ma}$ ) [26]. Ribesalbes oil shales were taken from a basin located in the southern part of the Iberian chain wich belongs to the Miocene lacustrine system (ca. $10 \mathrm{Ma}$ ) [27].

Mequinenza coal and Ribesalbes oil shales are characterized by a high sulfur content $\left(\mathrm{S}_{\text {org }} / \mathrm{C}>0.04,[28]\right)$. Sulfur influence on kinetic parameters at the maximum temperature of the DTG curve is reported elsewhere $[29,30]$.

All experiments were performed with a CAHN thermobalance TG-151 attached to an analytical thermal system [19]. The specifications of the equipment are: balance capacity: $100 \mathrm{~g}$; sensitivity: $10 \mu \mathrm{g}$; maximum temperature $(\mathrm{P}=1 \mathrm{bar}): 1100{ }^{\circ} \mathrm{C}$; maximum heating rate: $25 \mathrm{~K} / \mathrm{min}$; crucible: quartz $(\mathrm{CAHN})$. Thermal experiments were conducted with a sample size between 26 and $27 \mathrm{mg}$ in the temperature range $298-1123 \mathrm{~K}$. The analysis were carried out at three constant heating rates $(5,15$ and $25 \mathrm{~K} / \mathrm{min})$ and with a nitrogen purge flow of $200 \mathrm{ml} / \mathrm{min}$. For each sample, two reproducible experiments were carried out. The mean accuracy of the experiments was $10 \%$.

The program used in order to treat the experimental data was Micro-Cal Origin 3.0. Kinetic parameters were calculated in the interval related with oil and hydrocarbon generation: from 450 to $700 \mathrm{~K}$ for Mequinenza and Cañizara coals and from 700 to $850 \mathrm{~K}$ for Ribesalbes oil shales.

Simnon program [31] was used to simulate Eq. (7), (8) and (11) based on two differential methods and the integral method, respectively. The simulation of these equations permits to establish the most accurate methods and the comparison among them. Simnon is a special language for solving ordinary differential (is specified as a continuous system) and difference equations (is specified as a discrete system) and for simulating dynamic systems.

According to the language Simnon, Eq. (7) can be expressed as the continuous time system described in the simulation scheme 1 (see Appendix). The system description has two parts, a declaration and a body. A time variable may be declared for simulation of time varying differential equations. This is done by the keyword TIME (corresponds to temperature in nonisothermal experiments) followed by an identifier. The state variables and their derivatives are declared by the keywords STATE and DER followed by a list of the state variables and the derivatives. The body system description specifies the derivatives of the state variables in terms of state variables and parameters. The body also contains assignment of parameters and initial values.

Nevertheless, Eq. (8) is also described as a continuous system. Since Eq. (8) is of second order, an extra variable has to be introduced. Choosing this variable as $y=\mathrm{d} x / \mathrm{d} t$, Eq. (8) can be written as the form depicted in simulation scheme 2 (see Appendix).

Eq. (11) is described as a difference equation. A difference equation is characterized as a discrete system in Simnon. Apart from the simulation of $g(\alpha)$ one must take into account the extent of conversion with temperature 
because it is a intrinsic variable associated to $g(\alpha)$ variable. The simulation of the conversion with temperature consists on writing Eq. (6) in a discrete form:

$$
\frac{\alpha_{m}-\alpha_{n}}{T_{m}-T_{n}}=\frac{A}{\beta}(1-\alpha)^{n} e^{-E / R T}
$$

The description of a system which simulates the difference Eqs. (11) and (21) is given in simulation scheme 3 (see Appendix). The state variable is declared in the same way as for continuous time system using STATE declaration. The declaration NEW is used to declare the variable $n x$, which denotes the new value of the state variable. New is also the analog of DER for continuous time systems. In simulation scheme 3 the first assignment statement is simply a definition of the right hand side of the difference Eqs. (11) and (21). The second line: $t \mathrm{~s}=k+1$ assigns the value $k+1$ to the TSAMP variable $t$ s. This variable gives the time when the system is next activated.

\section{Discussion and comparison of methods}

Figure 2 shows TG/DTG curves of the representative sample from Cañizara during the pyrolysis at $15 \mathrm{~K} / \mathrm{min}$ heating rate. Maximum temperatures obtained from TG/DTG curves at different heating rates are shown in Table 2 .

Kinetic parameters calculated using Eq. (7) indicate a systematic decrease of $\ln \mathrm{A}$ and $\mathrm{E}$, with increasing of heating rate (Table 3). This decreasing tendency of the kinetic parameters with heating rate was also observed using Eq. (8) and Eq. (11) [26]. This is a familiar manifestation of the

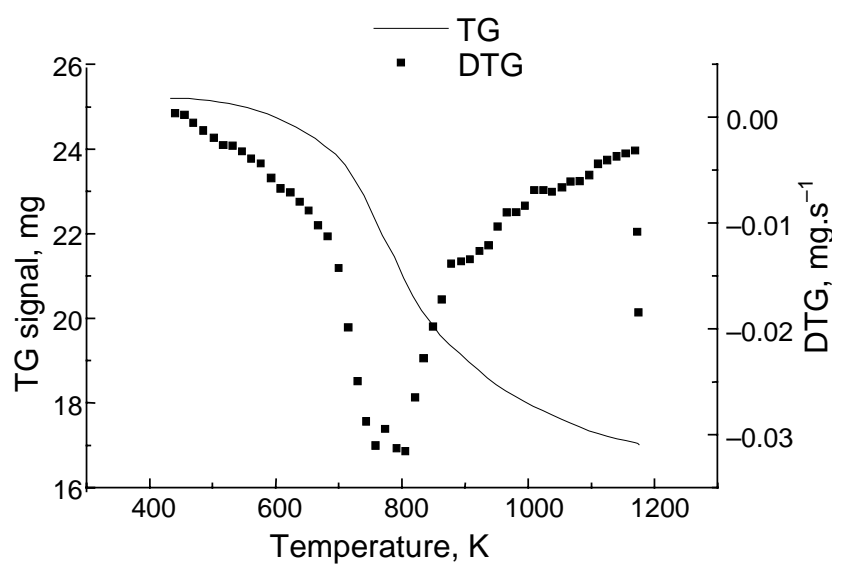

Fig. 2. TG/DTG curves of Utrillas (Cañizara) coal at heating rate $15 \mathrm{~K} / \mathrm{min}$. 
Table 2. Maximum temperatures (K) of TG/DTG curves obtained at 5,15 and $25 \mathrm{~K} / \mathrm{min}$ and percentages of mass loss for Mequinenza and Cañizara coals and Ribesalbes oil shales

\begin{tabular}{|l|c|c|c|c|}
\hline \multirow{2}{*}{ Sample } & \multicolumn{3}{|c|}{ Heating rate, K/min } & \multirow{2}{*}{ Mass loss, \% } \\
\cline { 2 - 4 } & 5 & 15 & 25 & \\
\hline 8-Me & 710 & 739 & 755 & 40 \\
Cañizara & 742 & 769 & 782 & 32 \\
Rib-3 & 759 & 802 & 807 & 39 \\
Rib-7 & 754 & 788 & 807 & 29 \\
\hline
\end{tabular}

Table 3. Kinetic parameters calculated using the differential method based on Eq. (7) at heating rates 5, 15 and $25 \mathrm{~K} / \mathrm{min}$ for Cañizara and Mequinenza coals and Ribesalbes oil shales

\begin{tabular}{|l|r|r|r|}
\hline \multicolumn{1}{|c|}{ Heating rate } & $5 \mathrm{~K} / \mathrm{min}$ & $15 \mathrm{~K} / \mathrm{min}$ & $25 \mathrm{~K} / \mathrm{min}$ \\
\hline \multicolumn{1}{|c|}{$8-\mathrm{Me}:$} & & & \\
$T_{\text {iso }}, \mathrm{K}$ & 601.39 & 601.39 & 601.39 \\
$E_{a}, \mathrm{~kJ} / \mathrm{mol}$ & 134.49 & 104.665 & 82.36 \\
$\ln A, 1 / \mathrm{min}$ & 21.89 & 16.95 & 13.15 \\
$\ln k_{i}$ & -5.00 & -3.98 & -3.32 \\
\hline \multicolumn{1}{c}{ Cañizara: } & & & \\
$T_{\text {iso }}, \mathrm{K}$ & 1202.79 & 1202.79 & 1202.79 \\
$E_{a}, \mathrm{~kJ} / \mathrm{mol}$ & 104.14 & 88.13 & 85.68 \\
$\ln A, 1 / \mathrm{min}$ & 15.25 & 12.91 & 12.86 \\
$\ln k_{i}$ & 4.83 & 4.09 & 4.91 \\
\hline \multicolumn{1}{|c|}{$\mathrm{Rib}-3:$} & & & \\
$T_{\text {iso }}, \mathrm{K}$ & 601.39 & 601.39 & 601.39 \\
$E_{a}, \mathrm{~kJ} / \mathrm{mol}$ & 245.2 & 304.34 & 98.16 \\
$\ln A, 1 / \mathrm{min}$ & 40.90 & 52.60 & 14.55 \\
$\ln k_{i}$ & -8.14 & -8.27 & -5.08 \\
\hline \multicolumn{1}{|c|}{$\mathrm{Rib}-7:$} & & & \\
$T_{\text {iso }}, \mathrm{K}$ & 601.39 & 601.39 & 601.39 \\
$E_{a}, \mathrm{~kJ} / \mathrm{mol}$ & 261.79 & 189.75 & 250.06 \\
$\ln A, 1 / \mathrm{min}$ & 41.42 & 28.77 & 39.21 \\
$\ln k_{i}$ & -10.94 & -9.18 & -10.80 \\
\hline
\end{tabular}

compensation effect, discussed in detail elsewhere [22]. Both this decrease and the related compensation effect can result from an increased thermal lag at higher heating rates [32].

$\operatorname{Ln} A$ and $E$ values obey a linear kinetic compensation effect as [33]

$$
\ln A=a+b E,
$$

where $a=\ln k_{i}, b=1 / R T_{i}$.

This indicates the existence of an isokinetic temperature $\left(T_{i}\right)$, because in the case of a series of pyrolysis processes there is a temperature $T_{i}$ at which the rate constant exhibits the same value $k_{i}$. Eq. (22) implies a variation of the activation energy with the preexponential factor, so that both parameters 
vary parallelly in order to keep reaction rate constant $k\left(a=\ln k_{i}\right)$. Thus, the kinetic parameters will be more reliable when the reaction rates $\left(\ln k_{i}\right)$ at different heating rates are constant or practically equal. Table 3 shows that samples with $\ln k_{i}$ more equal in the three heating rates are Cañizara coal and Rib-7 oil shale. However, Mequinenza coal and Rib-3 oil shale do not show a large variation.

Figure 3 shows a plot of $\ln A$ vs $E$ for the data collected in this study at the single curves methods at different heating rates $(5,15$ and $25 \mathrm{~K} / \mathrm{min})$ by using differential method based on Eq. (7) and the integral based on Eq. (11). The equation of the linear regression analysis shown in Fig. 3 is

$$
\ln A=0.17 E-2.5,
$$

where $E$ is expressed in $\mathrm{kJ} / \mathrm{mol}$ and $A$ in $1 / \mathrm{min}$.

Data can be expressed according to the compensation effect $[4,34]$ when, as a result of procedural changes, nonisothermal experiments modifies the apparent activation energy and apparent preexponential factor. This compensation effect can be used to explain the relative magnitudes of the $E$ values from two pairs of analytical methods. As it is shown in Fig. 3, the same compensation effect (Eq. (23)) affects equally both differential (Eq. (7)) and integral (Eq. (11)) methods. It means that the kinetic parameters can be compared because the relative magnitudes of the $E$ are influenced by a similar relationship.

Table 4 shows mean values of apparent activation energies at 5, 15 and $25 \mathrm{~K} / \mathrm{min}$ heating rates calculated by methods based on a single curve (Eq. (7), Eq (8) and Eq (11)). Low correlation coefficients $\left(R^{2}<0,6\right)$ were obtained by Eq. (8) [29]. The differences between apparent activation energies estimated by means of differential (Eq. (7)) and integral (Eq. (11)) methods from a single curve are relatively small except in the case of Rib-7 which shows a larger variation $(234 \mathrm{~kJ} / \mathrm{mol}$ for differential method and $384 \mathrm{~kJ} / \mathrm{mol}$ for integral method) (Table 4). This difference could be attributed to a more complex nature of Rib-7 degradation and due to the fact

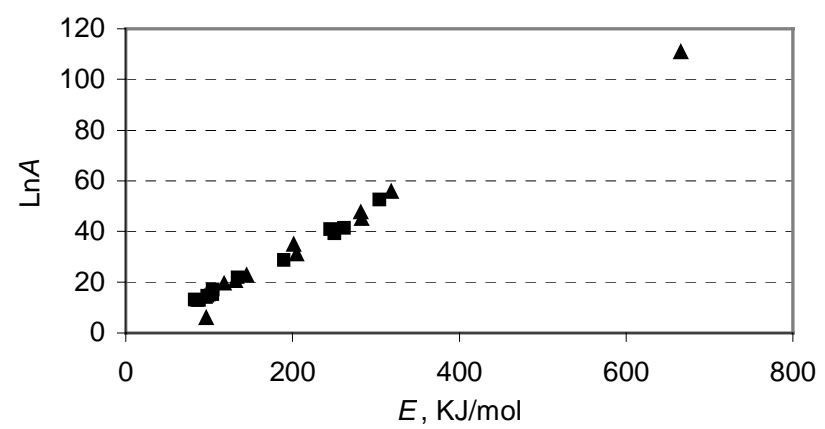

Fig. 3. Correlation of kinetic parameters of all samples. - - differential method (Eq. (7)); $\boldsymbol{\Delta}$ - integral method (Eq. (11)). 
Table 4. Mean values of the apparent activation energies $(\boldsymbol{E}, \mathbf{k J} / \mathbf{m o l})$ and correlation coefficients (in brackets) obtained basing on TG single curves at 5 , 15 and $25 \mathrm{~K} / \mathrm{min}$ and calculated by differential methods based on Eq. (7) and Eq. (8), respectively, and integral method based on Eq. (11)

\begin{tabular}{|l|c|c|c|}
\hline \multirow{2}{*}{ Samples } & \multicolumn{3}{|c|}{ Methods } \\
\cline { 2 - 4 } & $M d_{m}$ (Eq. 7) & $M d_{m}$ (Eq. 8) & $M i_{m}$ (Eq. 11) \\
\hline 8-Me & $107(0.99)$ & $64(0.5)$ & $138(0.99)$ \\
Cañizara & $93(0.99)$ & $66(0.65)$ & $108(0.99)$ \\
Rib-3 & $216(0.97)$ & $388(0.4)$ & $248(0.97)$ \\
Rib-7 & $234(0.99)$ & $145(0.5)$ & $384(0.99)$ \\
\hline
\end{tabular}

that multiple reactions that take place could be responsible of the higher activation energy and, as well less representative of the real value [35].

As it is shown in Fig. 4, 5 and 6, the simulation of these equations demonstrates that the differential method based on Eq. (7) followed by the integral one based on Eqs. (11) and (21) offer a good fit to experimental data. In contrast, differential method described by Eq. (8) shows that this method offers a larger variation compared to the experimental curves (Fig. 4, 6). This fact contrasts with the criteria made by Popescu and Segal [11] who report that the differential method based on Eq. (8) offers a high degree of approximation because more approximations (method value) are used than anyone in order to derive the equation upon which it is based. According to these results, the method value used by Popescu and Segal [11] is not a suitable parameter to establish the validity of the kinetic method, and a factor would be necessary to evaluate the calculation of the derivatives.

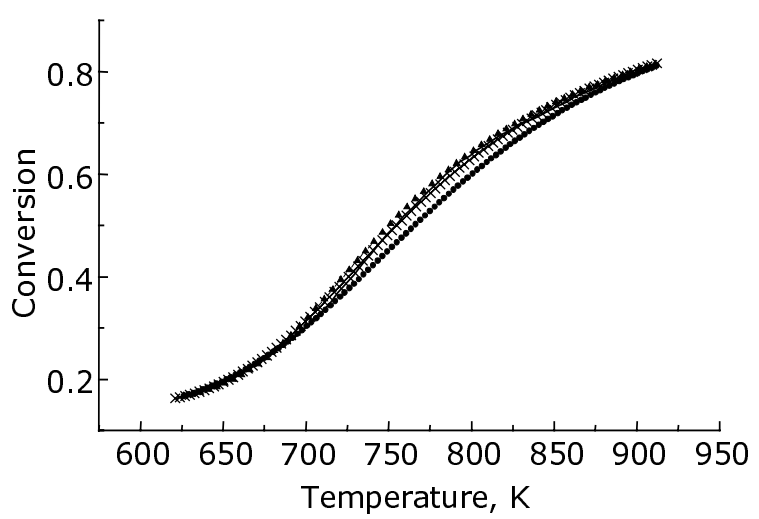

Fig. 4. TG curve recorded experimentally (- ) and simulation of the Eq. (7) (x; $\left.E_{a}=104.14 \mathrm{~kJ} / \mathrm{mol}, \ln A, 1 / \mathrm{min}=15.25\right) ; \mathrm{Eq} .(8)\left(\bullet ; E_{a}=74.16 \mathrm{~kJ} / \mathrm{mol}\right) ;$ and Eqs. (11) and (21) $\left(\boldsymbol{\Delta} ; E_{a}=131.41 \mathrm{~kJ} / \mathrm{mol}, \ln A, 1 / \mathrm{min}=20.37\right)$ at $5 \mathrm{~K} / \mathrm{min}$ for Cañizara coal. 


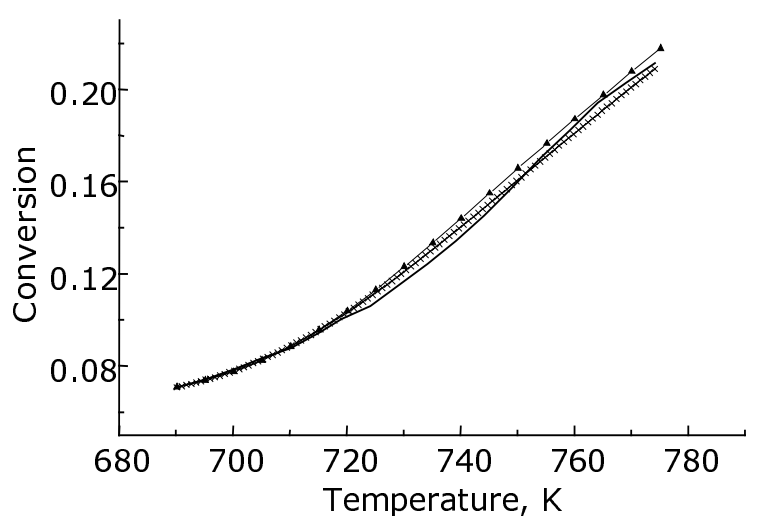

Fig. 5. TG curve recorded experimentally ( $)$ and simulation of the Eq. (7) (x; $\left.E_{a}=261.79 \mathrm{~kJ} / \mathrm{mol}, \ln A, 1 / \mathrm{min}=41.42\right) ;$ and Eqs. (11) and (21) $\left(\boldsymbol{\Delta} ; E_{a}=282.35\right.$ $\mathrm{kJ} / \mathrm{mol}, \ln A, 1 / \mathrm{min}=44.93$ ) at $5 \mathrm{~K} / \mathrm{min}$ for Ribesalbes- 7 oil shale.

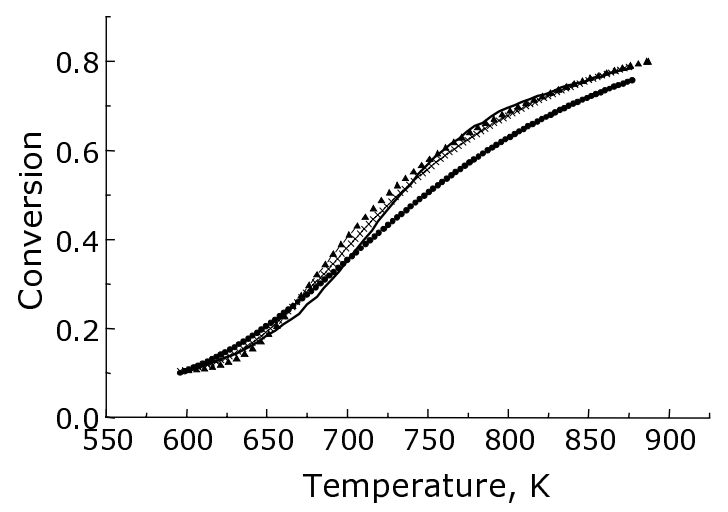

Fig. 6. TG curve recorded experimentally ( - ) and simulation of the Eq. (7) (x; $\left.E_{a}=134.49 \mathrm{~kJ} / \mathrm{mol}, \ln A, 1 / \mathrm{min}=21.89\right) ;$ Eq. (8) $\left(\bullet ; E_{a}=65.68\right)$; and Eqs. (11) and (21) $\left(\boldsymbol{\Delta} ; E_{a}=282.35 \mathrm{~kJ} / \mathrm{mol} ; \ln A, 1 / \mathrm{min}=44.93\right)$ at $5 \mathrm{~K} / \mathrm{min}$ for Mequinenza coal.

Recently, differential methods have been applied to determine activation energies from Turkish coals and oil shales [21]. Although it is difficult to compare different samples because different equipment has been used, activation energies from experiments with Himmetoglu oil shale [21] were found to be similar $(215.4 \mathrm{~kJ} / \mathrm{mol})$ to those obtained for Ribesalbes oil shale.

Table 5 shows the values of apparent activation energies calculated from several curves. It is also observed that the multiple heating rate methods give higher values of $E$ than those obtained from a single curve analysis except in Rib-3 oil shale. The most reasonable agreement for all methods is given for Rib-7 oil shale. Methods based on several curves give higher values of $E$ than the single curve method as it has been reported previously $[4,5]$. The values of the apparent activation energies obtained by the differential and integral methods using conversion $=$ constant $(\alpha=\mathrm{c} t)$ are in good agreement. 
These differences appear more significant when the method is differential using temperature $=$ constant $(T=\mathrm{c} t)$. This method gives an unreliable activation energy (negative value) for Rib-3 oil shale.

Table 5. Mean values of apparent activation energies $(\boldsymbol{E}, \mathbf{k J} / \mathbf{m o l})$ and correlation coefficients (in brackets) calculated by the differential methods (Eq. (13), Eq. (14)) and integral methods (Eq. (19) and Eq. (20)) based on several curves at heating rates 5,15 and $25 \mathrm{~K} / \mathrm{min}$

\begin{tabular}{|l|c|c|c|c|}
\hline \multirow{3}{*}{ Sample } & \multicolumn{2}{|c|}{ Differential methods } & \multicolumn{2}{c|}{ Integral methods } \\
\cline { 2 - 5 } & $\begin{array}{c}T_{c t} \\
\text { Eq. (13) }\end{array}$ & $\begin{array}{c}C_{c t} \\
\text { Eq. (14) }\end{array}$ & $\begin{array}{c}\Delta T_{c t} \\
\text { Eq. (19) }\end{array}$ & $\begin{array}{c}\Delta C_{c t} \\
\text { Eq. (20) }\end{array}$ \\
\hline 8.Me & $661(0.99)$ & $518(0.99)$ & $350(0.99)$ & $484(0.98)$ \\
Cañizara & $207(0.99)$ & $298(0.99)$ & $107(0.98)$ & $273(0.96)$ \\
Rib-3 & -354 & n.c. & $231(0.98)$ & $325(0.95)$ \\
Rib-7 & $286(0.99)$ & $195(0.99)$ & $240(0.95)$ & $216(0.95)$ \\
\hline
\end{tabular}

n.c. - not calculated

Although many authors show disagreement with the methods based on several curves since they do not give coherent results [4], other authors confirm the reliability of these methods since in the case of certain coals they allow to obtain more information on the processes of pyrolysis than methods based on a single curve $[16,36-38]$.

\section{Conclusions}

Six different linear methods proposed in the literature were used to simulate pyrolysis of Spanish fossil fuels: three methods based on several curves and three based on a single curve. The simulation of Eq. (7), Eq. (8) and Eqs. (11) and (21) using Simnon program allowed us to establish the most accurate method. The results indicate that the most reliable methods based on a single TG curve were the differential (Eq. (7)) followed by the integral one (Eq. (11)). In contrast, the least accurate methods were the differential from a single experimental curve (Eq. (8)) and several curves (Eq. (14)). Rib-7 oil shale gave the most reasonable agreement for all methods.

\section{Acknowledgements}

The authors thank E. Velo, A. Manyà and L. Puigjaner from the Laboratory of Thermogravimetry of the Escola Tècnica Superior d'Enginyers Industrials de Barcelona (UPC) for their technical support with TG experiments. This research was financed by the Spanish CICYT (project CTQ2005-08957$\mathrm{C} 02-02)$. 


\section{Appendix}

Simulation scheme 1. Simulation of Eq (7) for Mequinenza coal at $5 \mathrm{~K} / \mathrm{min}$ in Simnon program

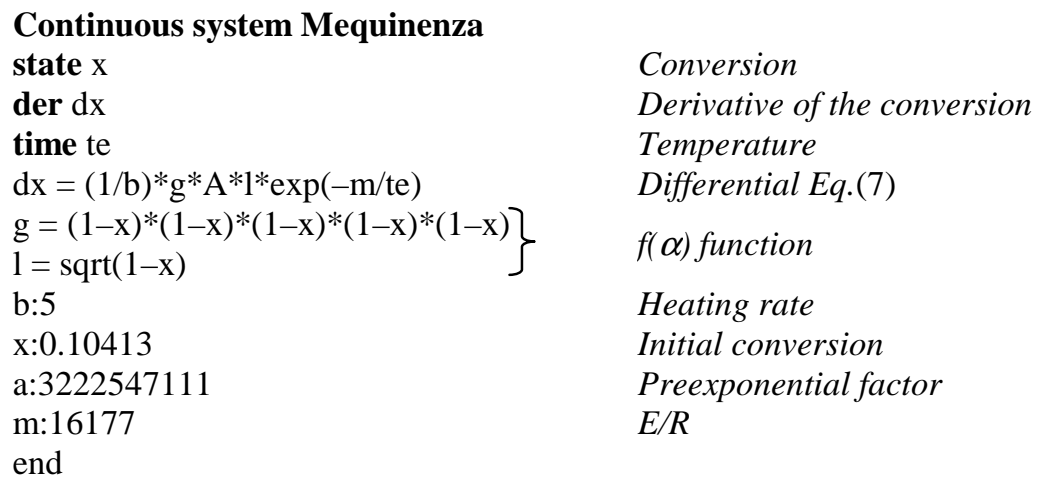

Simulation scheme 2. Simulation of Eq. (8) for Mequinenza coal at $15 \mathrm{~K} / \mathrm{min}$ in Simnon program

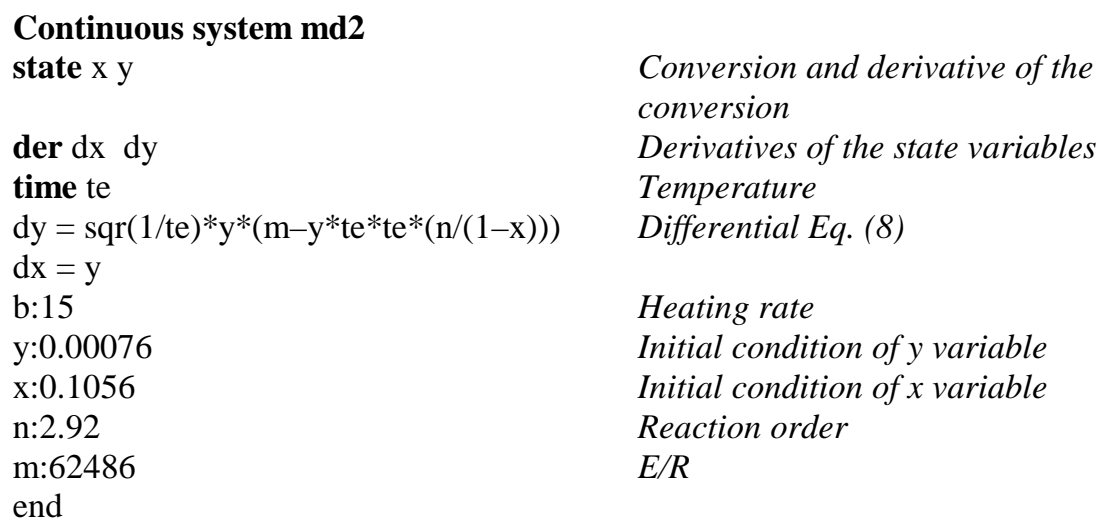

m:62486 E/R

Conversion and derivative of the conversion

Derivatives of the state variables

Temperature

Differential Eq. (8)

Simulation scheme 3. Simulation of Eq. (11) and Eq. (21) for Mequinenza coal at $5 \mathrm{~K} / \mathrm{min}$ in Simnon program

\section{Discrete system integral}

\section{state $\mathrm{g} x$}

New ng nx

time te

\section{TSAMP ts}

ng $=\mathrm{g}+(1 / \mathrm{b}) * \mathrm{~A}^{*}(\mathrm{ts}-\mathrm{te}) * \exp (-\mathrm{m} / \mathrm{ti})$

$\mathrm{nx}=\mathrm{x}+(1 / \mathrm{b}) * \mathrm{f} * \mathrm{r} * \mathrm{~A} *(\mathrm{ts}-\mathrm{te}) * \exp (-\mathrm{m} / \mathrm{ti})$

$\mathrm{f}=\operatorname{sqr}((1-\mathrm{x}) *(1-\mathrm{x}))$

$r=\operatorname{sqrt}(\operatorname{sqrt}((1-\mathrm{x}) *(1-\mathrm{x}) *(1-\mathrm{x})))\}$

\author{
$g$ and $x$ (conversion) \\ Derivatives of $g$ and $x$ \\ Temperature
}

Eq.(11)

Eq.(21)

Function $f(\alpha)$ 


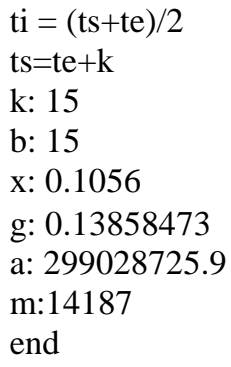

\author{
The next sampling time \\ Changes periodically at $k$ \\ Heating rate \\ Initial conversion \\ Initial condition of $g(\alpha)$ \\ Preexponential Factor \\ $E / R$
}

\section{REFERENCES}

1. Šesták, J., Šatava V. V., Wendlandt, W. W. The study of heterogeneous processes by thermal analysis // Thermochim. Acta. 1973. Vol. 7, No. 5. P. 333336.

2. Brown, M. E., Dollimore, D., Galwey, A. K. Reactions in the solid state. Comprehensive Chemical Kinetics (Ed. Brown, M.E.). Elsevier, Amsterdam, 1980. 356 pp.

3. Šesták, J., Berggren, G. Study of the kinetics of the mechanism of solid-state reactions at increasing temperatures // Thermochim. Acta. 1971. Vol. 3, No. 1. P. 1-12.

4. Zsakó, J. Kinetic analysis of thermogravimetric data. XXIX. Remarks on the 'many curves` methods // J. Thermal Anal. Cal. 1996. Vol. 46, No. 6. P. 18451864.

5. Vyazovkin, S. V., Linert, W. Detecting isokinetic relationships in non-isothermal systems by isoconversional method // Thermochim. Acta. 1995. Vol. 269-270. P. 61-72.

6. Kök, M. V. Thermal analysis applications in fossil fuel science // J. Therm. Anal. Cal. 2002. Vol. 68, No. 3. P. 1061-1077.

7. Fuller, E. L., Kopp, O. C., Rogers, M. R. Thermogravimetric and mass spectroscopic analysis of solvent refined Powellton coal, West Virginia (U.S.A.) / J. A. Pajares, J. M. D. Tascón (Eds.). Coal Science, Elsevier, Oviedo, 1995. P. 889-900.

8. Kök, M. V., Okandan, E. Kinetic analysis of DSC and thermogravimetric data on combustion of lignite // J. Therm. Anal. Cal. 1996. Vol. 46, No. 6. P. 16571669.

9. Kök, M. V. Thermal analysis of Beypazari lignite // J. Therm. Anal. Cal. 1997. Vol. 49, No. 2. P. 617-625.

10. Kök, M. V. Evaluation of Turkish oil shales. Thermal analysis approach // Oil Shale. 2001. Vol. 18, No. 2. P. 131-138.

11. Popescu, C., Segal, E. Critical considerations on the methods for evaluating kinetic parameters from nonisothermal experiments // Int. J. Chem. Kinet. 1998. Vol. 30, No. 5. P. 313-327

12. Friedman, H. L. Kinetics of thermal degradation of char-forming plastics from thermogravimetry. Application to phenolic plastic // J. Pol. Sci. 1964. Vol. 6C. P. 183-195.

13. ASTM E 698-79. Standard Test Method for Arrhenius Kinetic Constants for Thermally Unstable Materials. 1979. 
14. Rogers, R. N., Smith, L. C. Estimation of preexponential factor from thermal decomposition curve of an unweighed sample // Anal. Chem. 1967. Vol. 39, No. 8. P. 1024-1025.

15. Pérez-Maqueda, L. A., Sánchez-Jiménez, P. E., Criado, J. M. Evaluation of the integral methods for the kinetic study of thernally stimulated processes in polymer science // Polymer. 2005. Vol. 46, No. 9. P. 2950-2954.

16. Wu, C. S., Liu, Y. L., Hsu, K. Y. Maleimide-epoxy resins: preparation, thermal properties, and flame retardance // Polymer. 2003. Vol. 44, No. 3. P. 565-573.

17. Chang, T. C., Yeh, T. F., Yang, C.W., Hong, Y. S., Wu, T. R. Chain dynamics and stability of the poly (3-methacryloxypropyltrimethoxysilane-co-vinylimidazole) // Polymer. 2001. Vol. 42, No. 21. P. 8565-8570.

18. Zvetkov, V. L. Comparative DSC kinetics of the reaction of DGEBA with aromatic diamines. I. Non-isothermal kinetic study of the reaction of DGEBA with $m$-phenylene diamine // Polymer. 2001. Vol. 42, No. 16. P. 6687-6697.

19. Kök, M. V., Pamir, R. Pyrolysis kinetics of oil shales determined by DSC and TG/DTG // Oil Shale. 2003. Vol. 20, No. 1. P. 57-68.

20. Kök, M. V., Pokol, G., Keskin, C., Madarász, J. Bagci, S. Combustion characteristics of lignite and oil shale samples by thermal analysis techniques // J. Therm. Anal. Cal. 2004. Vol. 76, No. 1. P. 247-254.

21. Kök, M. V., Iscan, A. G. Oil shale kinetics by differential methods // J. Therm. Anal. Cal. 2007. Vol. 88, No. 3. P. 657-661.

22. Olivella M. A., de las Heras, F.X.C. Nonisothermal thermogravimetry of Spanish fossil fuels // Oil Shale. 2006. Vol. 23, No. 4. P. 340-355.

23. Vachuška, J., Voboril, M. Kinetic data computation from non-isothermal thermogravimetric curves of non-uniform heating rate// Thermochim. Acta. 1971. Vol. 2, No. 5. P. 379-392.

24. Popescu, $C$. Integral method to analyze the kinetics of heterogeneous reactions under non-isothermal conditions. A variant on the Ozawa-Flynn-Wall method // Thermochim. Acta. 1996. Vol. 285, No. 2. P. 309-323.

25. Querol, X., Cabrera, L., Pickel, W., López-Soler, A., Hagemann, H. W., Fernández Turiel, J. L. Geological controls on the coal quality of the Mequinenza subbituminous coal deposit, northeast Spain // Int. J. Coal Geol. 1996. Vol. 29, No. 1-3. P. 67-91.

26. Querol, X., Chinchón, S., López-Soler, A. Iron sulfide precipitation sequence in Albian coals from the Maestrazgo Basin, Southeastern Iberian Range, Northeastern Spain // Int. J. Coal Geol. 1989. Vol. 11, No. 2. P. 171-189.

27. Anadón, P., Cabrera, L., Julià, R., Roca, E., Rosell, L. Lacustrine oil shale basins in tertiary grabens from NE Spain (Western European rift system) // Palaeogeogr. Palaeoclimat. Palaeocol. 1989. Vol. 70, No. 1-3. P. 7-28.

28. $\operatorname{Orr}$ W. L. Kerogen/asphaltene/sulfur relationships in sulfur-rich Monterey oils // Org. Geochem. 1986. Vol. 10, No. 1-3. P. 499-516.

29. Olivella, M. A. Study of sulfur in fossil fuels. PhD. Thesis, Universitat Politècnica de Catalunya (ed), Manresa, 2000. 325 pp.

30. Olivella, M. A., de las Heras, F.X.C. Kinetic analysis in the maximum temperature of oil generation by thermogravimetry in Spanish fossil fuels // Energy \& Fuels. 2002. Vol. 16, No. 6. P. 1444-1449.

31. Elmqvist, H., Aström, K. J., Schönthal, T. Simnon User's Guide for MS-DOS computers, version 1. - Ed. Department of Automatic Control. Sweden, 1986. 
32. Narayan, R., Antal, M.J. Thermal lag, fusion and the compensation effect during biomass pyrolysis // Ind. Eng. Chem. Res. 1996. Vol. 35, No. 5. P. 17111721.

33. Zsakó, J., Várhelyi, Cs; Kékedy, E.; Szilágyi, K. Kinetic analysis of thermogravimetric data. XXIX. Remarks on the many curves methods // J. Thermal Anal. Cal. 1975. Vol. 7, 41-50.

34. Mianowski, A., Radko, T. Isokinetic effect in coal pyrolysis // Fuel. 1993. Vol. 72, No. 11. P. 1537-1539.

35. Wilburn, $F$. W. The determination of kinetic parameters from DTG curves - fact or fiction? // Thermochim. Acta. 1999. Vol. 340-341. P. 77-87.

36. Vyazovkin, S., Linert, W. Kinetic analysis of reversible thermal decomposition of solids // Int. J. Chem. Kinet. 1995. Vol. 27, No. 1. P. 73-84.

37. Criado, J. M., Ortega, A., Gotor, F. Correlation between the shape of controlled rate thermal analysis curves and the kinetics of solid state reactions // Thermochim. Acta. 1990. Vol. 157, No. 1. P. 171-179.

38. Vyazovkin, $S$. A unified approach to kinetic processing of non-isothermal data // Int. J. Chem. Kinet. 1996. Vol. 28, No. 2. P. 95-101.

Presented by M. V. Kök

Received October 16, 2007 